\title{
NITROGENING HYDRAULIC CYLINDER RODS
}

\author{
Yurov V.M. ${ }^{1}$, Guchenko S.A. ${ }^{1}$, Salkeeva A.K. ${ }^{2}$, Kusenova A.S. ${ }^{2}$ \\ ${ }^{1}$ E.A. Buketov Karaganda University, Karaganda, Kazakhstan, exciton@list.ru \\ ${ }^{2}$ Karaganda Technical University, Karaganda, Kazakhstan, salkeeva58@mail.ru
}

\begin{abstract}
The paper considers the method of ion-plasma nitriding of polished rods of hydraulic cylinders. With ion nitriding, the surface hardening of parts is most pronounced. This is due to the fact that the surface layer of the part does not exceed $20 \mathrm{~nm}$, that is, it is a nanostructure. In this nanostructure, nitrogen diffusion processes are significantly different from bulk ones. The size effects in the nanostructure lead to the fact that the "classical" Fick equations do not work in the layer, and the diffusion of nitrogen in this layer depends logarithmically on the properties of the steel. It was theoretically found that diffusion in a nanoplate depends both on the material of the plate through the diffusion coefficient of the bulk sample $D_{0}$ and on the size factor $\alpha$. In the classical case, there is no such dependence.
\end{abstract}

Keywords: nitriding, detail, surface layer, nanostructure, diffusion, nitrogen, size factor, steel.

\section{Introduction}

The surface is the most important component of metal parts and it is necessary to control its condition at all stages of the part's life cycle - during its production, operation and repair [1]. The surface layer of metal parts can be considered as a part of a solid, which includes its constituent molecules, atoms, protons, neutrons, electrons, vacancies, dislocations and other components, each of which has energy [2].

The surface of metal parts plays a special role in increasing their strength by the method of thermochemical action. The basis for such a functional impact is [3]:

- cementation (filling the surface layer with carbon);

- nitriding (filling the surface layer with nitrogen);

- nitrocarburizing or cyanidation (filling the surface layer with carbon and nitrogen simultaneously);

- diffusion metallization (filling the surface layer with various metals).

We will consider the strengthening of 35HGSA steels using ion nitriding [4]. It follows from the analysis of the literature that during ion nitriding, the surface hardening of parts and tools is most clearly manifested, which are constantly used in all industrialized countries instead of the usual methods of chemical-thermal treatment, which is often environmentally harmful.

\section{Experimental technique}

Ion-plasma nitriding was carried out on an NNV 6.6-I1 setup equipped with a plasma source with a hot cathode "PINK" [5], developed by ISE SB RAS (Fig.1). Plasma generator "PINK" can be installed on any of the three flanges of the NNV 6.6-I1 chamber. On the flange 6 there are two current leads 3 for heating the cathode 2. The hollow electrode 1 is also installed on the flange 6 . The direct-heated cathode is made of tungsten. The plasma generator is powered by a combined inverter power supply with a heating current adjustment range of 10-150 A and an ion current of 10-100 A.

Under the influence of an external magnetic field, the trajectory of electrons emitted from the heated cathode is bent. Electrons move along a cylindrical spiral, which increases their path to the anode, thereby increasing the efficiency of gas ionization. By changing the filament current, and hence the emission of electrons from the hot cathode, one can easily regulate the discharge current from tens to hundreds of amperes at a combustion voltage of several tens of volts. Such a discharge is classified as a non-selfsustaining hot-cathode arc discharge without a cathode spot. This arc discharge will make it possible to generate low-temperature plasma in volumes $\left(\geq 0.1 \mathrm{~m}^{3}\right)$ with a concentration of $\mathrm{n}_{\mathrm{e}} \sim 10^{9}-10^{11} \mathrm{~cm}^{-3}$ and a uniformity of $\pm 15 \%$ of the average value. 




a)

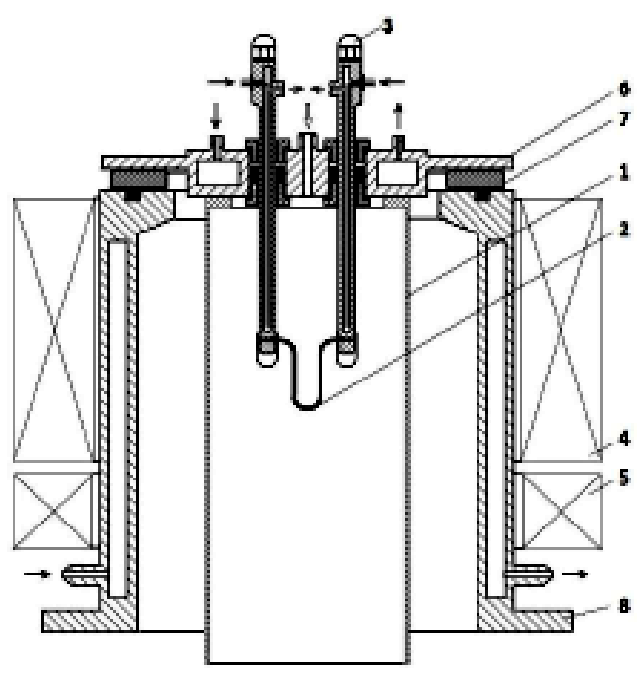

b)

Fig.1. Appearance (a) and schematic diagram (b) of the plasma source "PINK" [5].

1 - cathode cavity; 2 - hot tungsten cathode; 3 - electric input; 4 - stabilizing coil; 5 - focusing coil; 6 - watercooled flange; 7 - insulator; 8 - water-cooled housing.

\section{Technological mode of the nitriding process.}

Preliminary preparation:

1. Degreasing of stocks with Nefras S2-80/120.

2. Cleaning and polishing of 35HGSA rods in the bath of the EPP-40 electrolytic-plasma polishing unit, with the following parameters: the composition of the polishing solution $-5 \%$ aqueous solution of ammonium sulfate; solution temperature $-85^{\circ} \mathrm{C}$; cathode-anode voltage $300 \mathrm{~V}$, current $40 \mathrm{~A}$; processing time 5 min.

3. After unloading from the EPP-40 bath, the stocks are washed with running water and treated with steam using a steam jet device UPS 4.3-geyser.

4. After steam-jet cleaning, the rods are wiped with coarse calico moistened with alcohol and placed in a drying oven for drying and preheating to $150^{\circ} \mathrm{C}$.

\section{The process of ion-plasma nitriding.}

1. Prepared rods are installed in the vacuum chamber of the NNV 6.6-I1 installation (Fig. 2 a) using special equipment in the center of the rotating table (Fig. 2 b).

2. A foreline evacuation of the installation chamber is carried out to a pressure of $1 \mathrm{~Pa}$ (time is about 15 min.).

3. Further evacuation of the chamber is carried out by a high-vacuum diffusion pump to a pressure of $5 * 10^{-3} \mathrm{~Pa}$. (time $20-25 \mathrm{~min}$.).

4. Then, argon is injected into the chamber through the gas leak and with the help of the BUEN electromagnetic leak control unit the pressure in the chamber is maintained at $2 * 10^{-1} \mathrm{~Pa}$.

5. For the process of ionic cleaning and heating, a plasma source with a heated PINK cathode is switched on, a heating current of $120 \mathrm{~A}$ and an ion current of $5 \mathrm{~A}$ are set.

6. The block of the reference voltage is turned on and the bias voltage of $-1000 \mathrm{~V}$ is applied to the parts. To eliminate the formation of micro arcs on parts, the reference voltage unit operates in a pulsed mode with a frequency of $25 \mathrm{kHz}$ and a duty cycle of $80 \%$.

7. The table rotation drive is switched on and the speed is set to $5 \mathrm{rpm}$.

8. Within 5-7 minutes, the PINK ion current is gradually brought to 45-50 A, while the heating of the rods is monitored using a Smotrich 7 pyrometer focused on the part through the viewing window of the chamber.

9. When the temperature reaches $450{ }^{\circ} \mathrm{C}$ (time 20-25 min.), Nitrogen of special purity is admitted into the chamber through a parallel gas main, using the RRG-10 flow meter (nitrogen flow rate is set at $2 \mathrm{l} / \mathrm{min}$.), The pressure is maintained at the level of $1.8-2.2 * 10^{-1} \mathrm{~Pa}$. Thus, the regime of ion-plasma nitriding of parts 
in an argon-nitrogen gas mixture is established. Further, throughout the entire process, the temperature of the products is controlled, if necessary, adjusting the PINC current and the reference voltage.

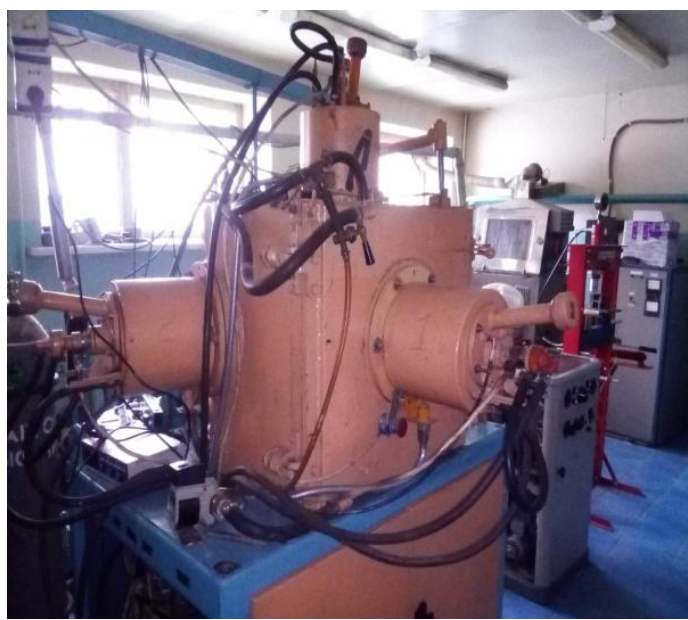

a)

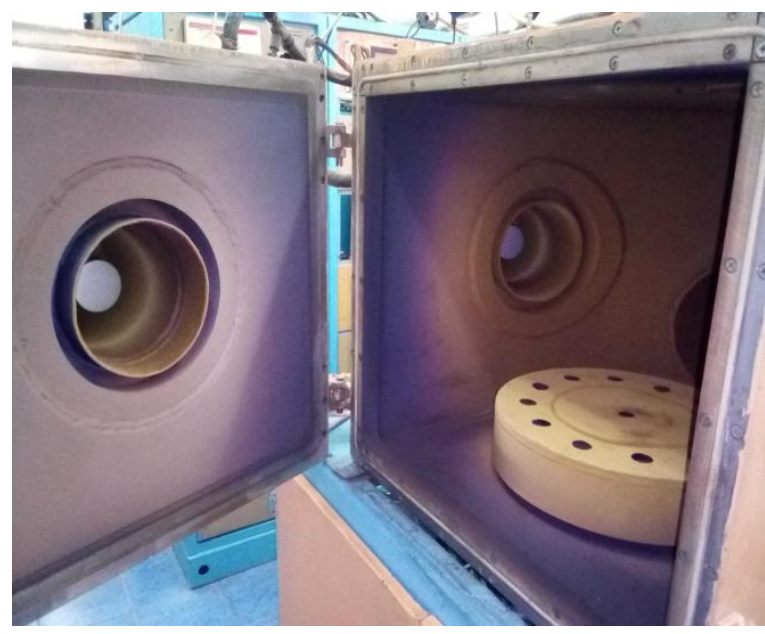

b)

Fig. 2. Vacuum chamber of the NNV 6.6-I1 installation (a) and the satellite of the rotating table (b)

The nitriding process lasts 3 hours, after which the products are allowed to cool in a vacuum chamber for an hour and unloaded. The stocks before and after nitriding are shown in Fig. 3.

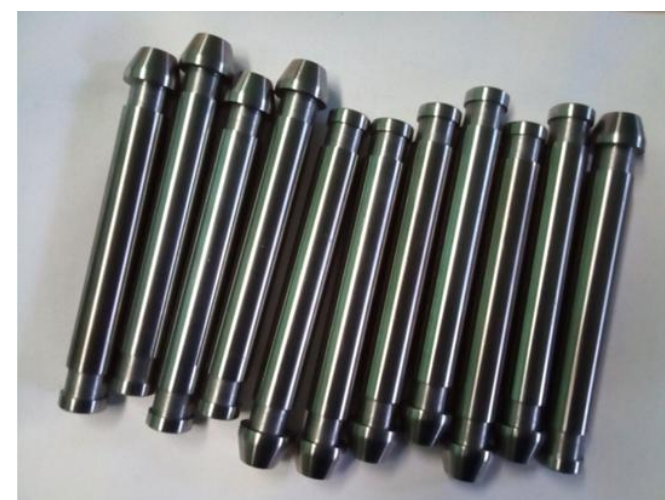

a)

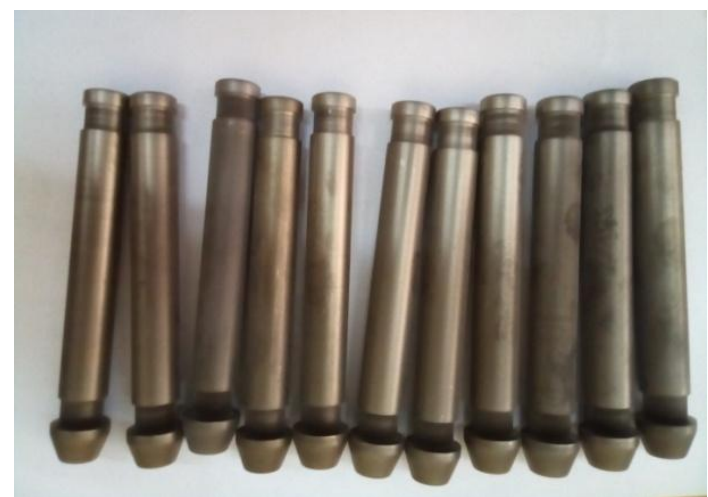

b)

Fig.3. Stocks 35HGSA before (260 HV) (a) and after (820 HV) (b) nitriding

The results of measurements of the microhardness of the hammer surface using an HV-1000 microhardness tester with a load on the indenter of $1 \mathrm{~kg}$ gave the following results: before nitriding about $260 \mathrm{HV}$, after about $820 \mathrm{HV}$ (Fig. 3).

\section{Discussion of the experimental results.}

\subsection{Surface layer thickness.}

In the introduction, we emphasized that the surface plays an important role in nitriding. In [5], we showed that for the dimensional dependence of a certain physical property of a solid $A(r)$, the following relations can be used:

$$
\begin{aligned}
& A(r)=A_{0} \cdot\left(1-\frac{d}{r}\right), r>d \\
& A(r)=A_{0} \cdot\left(1-\frac{d}{d+r}\right), r \leq d,
\end{aligned}
$$


The parameter $\mathrm{d}(\mathrm{nm})$, which we identify with the surface layer of an atomically smooth crystal, is related to the surface tension $\sigma$ by the formula:

$$
d=\frac{2 \sigma 0}{R T}
$$

Here $\sigma$ is the surface tension of a massive sample $\left(\mathrm{J} / \mathrm{m}^{2}\right) ; \mathrm{v}-$ molar (atomic) volume $\left(\mathrm{cm}^{3} / \mathrm{mol}\right) ; \mathrm{R}-$ gas constant $(\mathrm{J} / \mathrm{kg} \mathrm{K})$; $\mathrm{T}$ is temperature $(\mathrm{K})$.

It was shown in [5] that the following relation is fulfilled with high accuracy:

$$
\sigma=0.7 \cdot 10^{-3} \cdot T_{m},
$$

where $T_{m}$ is the melting point of the solid $(K)$. The ratio is fulfilled for all metals and for other crystalline compounds. If we substitute it in (2), then at $\mathrm{T}=\mathrm{T}_{\mathrm{m}}$ we get:

$$
d(I)=0.17 \cdot 10^{-9} \mathrm{v} .
$$

Equation (4) shows that the thickness of the surface layer $d(I)$ is determined by one fundamental parameter - the molar (atomic) volume of the element $(v=\mathrm{M} / \rho, \mathrm{M}$ is the molar mass $(\mathrm{g} / \mathrm{mol}), \rho$ is the density $\left.\left(\mathrm{g} / \mathrm{cm}^{3}\right)\right)$, which periodically changes in accordance with the table D.I. Mendeleev. The d(II) layer extends approximately to the size $\mathrm{d}(\mathrm{II}) \approx 10 \mathrm{~d}=\mathrm{d}_{\infty}$, where the bulk phase begins. Dimensional properties begin from this size. By nanomaterials it is customary to mean materials, the main structural elements of which do not exceed the nanotechnological boundary of $\sim 100 \mathrm{~nm}$, at least in one direction. Table 1 shows the $\mathrm{d}(\mathrm{I})$ and $\mathrm{d}(\mathrm{II})$ values of some metals and alloys.

Table 1 - Thickness of the surface layer of metals and alloys

\begin{tabular}{|c|c|c|c|c|}
\hline Steel, alloy & $\mathrm{M}, \mathrm{g} / \mathrm{mol}$ & $\rho, \mathrm{g} / \mathrm{cm}^{3}$ & $\mathrm{~d}(\mathrm{I}), \mathrm{nm}$ & $\mathrm{d}(\mathrm{II}), \mathrm{nm}$ \\
\hline 35HGSA & 52.60 & 7.85 & 1.14 & 11.4 \\
\hline $\mathrm{HG65MB}$ & 72.78 & 8.90 & 1.39 & 13.1 \\
\hline $\mathrm{W}_{90} / \mathrm{Ni}_{6} / \mathrm{Cu}_{4}$ & 171.66 & 17.10 & 1.71 & 17.1 \\
\hline $\mathrm{W}_{50} / \mathrm{Cu}_{50}$ & 123.75 & 11.85 & 1.78 & 17.8 \\
\hline
\end{tabular}

The thickness of the surface layer of metals and alloys d(I) and d(II) does not exceed 2 and $20 \mathrm{~nm}$, that is, it is a nanostructure, where it has been experimentally shown that diffusion processes are significantly different from bulk [6,7]. This especially affects the nitriding process of the metal rods studied by us [8].

\subsection{Diffusion in a metal plate of nanometer thickness.}

All manuals on the calculation of diffusion in thin coatings of space and aviation technology proceed from the classical Fick's equations, where the diffusion coefficient is considered a constant value [9]. As we have shown above, when the thickness of the metal film is less than $20 \mathrm{~nm}$, dimensional effects begin to affect its physical properties. Let us consider the problem of diffusion in an unbounded plate of thickness $\delta$. For simplicity and comparison, we restrict ourselves to the stationary case. Then the diffusion equation will have the form:

$$
\frac{d}{d x}\left(Д(x) \frac{d c}{d x}\right)=0
$$

In the classical case, $\mathrm{D}(\mathrm{x})=$ const, and in ours $-\mathrm{D}=\mathrm{D}_{0}(1-\alpha / \alpha+\mathrm{x})$. Here the size factor is denoted by $\alpha$ so as not to be confused with the differentiation sign. Taking into account the size effect (5) is reduced to the form:

$$
\frac{x}{x+\alpha} \frac{d c}{d x}=\frac{C_{1}}{Д_{0}}
$$

Here $\mathrm{C}_{1}$ is the constant of integration. The solution to equation (6) has the form:

$$
c(x)=\frac{C_{1}}{Д_{0}}(x+\alpha \ln x)+C_{2} .
$$

If in (5) $\mathrm{D}(\mathrm{x})=$ const, then we have the classical solution of the problem for an unbounded plate:

$$
c(x)=C_{1} x+C_{2} \text {. }
$$


In contrast to the classical problem, a logarithmic term appears in equation (7). This leads to a divergence at the origin. Therefore, the boundary conditions must be set not at $x=0$, but at $x=\lambda_{d B}-$ the de Broglie wavelength of electrons. Only in this case the classical Fick equations make sense.

It is also important that, according to (7), diffusion in a nanoplate depends both on the material of the plate through the diffusion coefficient of the bulk sample $\mathrm{D}_{0}$ and on the size factor $\alpha$. This leads to a difference in diffusion in the nanostructure $[6,7]$. In the classical case, there is no such dependence.

\subsection{The first boundary value problem for diffusion in a nanometer-thick wafer.}

To solve (7), the first boundary value problem will look like this:

$$
\begin{aligned}
& \left.c(x)\right|_{\mathrm{x}=\lambda_{\mathrm{dB}}}=\frac{C_{1}}{Д_{0}}\left(Д_{\mathrm{dB}}+\alpha \ln Д_{\mathrm{dB}}\right)+C_{2}=c_{1}, \\
& \left.c(x)\right|_{x=\delta}=\frac{C_{1}}{Д_{0}}(\delta+\alpha \ln \delta)+C_{2}=c_{2} .
\end{aligned}
$$

The general solution (9) (neglecting the de Broglie wave) will have the form:

$$
c(x)=\frac{\left(c_{1}-c_{2}\right)}{\delta} \cdot(x+d \ln x)+c_{1} .
$$

The general solution to the classical problem is:

$$
c^{1}(x)=\frac{c_{2}-c_{1}}{\delta} x+c_{1} .
$$

Comparison of (10) and (11) shows that diffusion in a nanometer-thick wafer differs significantly from a bulk sample. The difference between $\mathrm{c}(\mathrm{x})$ and $\mathrm{c}^{1}(\mathrm{x})$ at $\mathrm{x}=\mathrm{d}=\delta$ is:

$$
c(x)-c^{1}(x)=\left(c_{1}-c_{2}\right) \cdot \ln \mathrm{d} \text {. }
$$

\subsection{Diffusion of nitrogen in metals and alloys.}

The diffusion mobility of nitrogen will be proportional to the thickness of the surface layer $\mathrm{d}$. This value is associated with the crystal structure of the metal and, mainly, with its porosity. The existing nomenclature, adopted by the International Union of Theoretical and Applied Chemistry IUPAC, distinguishes three categories of pore size depending on their diameter: microporous $<2 \mathrm{~nm}$, mesoporous $2-50 \mathrm{~nm}$, and macroporous $>50 \mathrm{~nm}[10]$. An important characteristic of a metal is the degree of its porosity $\mathrm{P}$, defined as:

$$
P=1-\rho_{M e} / \rho_{K},
$$

where $\rho_{\mathrm{Me}}$ is the density of the porous metal (Me), $\rho_{\mathrm{K}}$ is the density of the single crystal.

If we substitute equation (13) into equation (4), we get [11]:

$$
d(I)_{K}=d(I)_{M e} /(1-P) .
$$

Typical porosity is $40-70 \%$, and with supercritical drying it reaches 95\%. Equation (14) yields the following table 2 .

Table 2 - Thickness of the surface layer of the rod 35HGSA at various values of porosity

\begin{tabular}{|c|c|c|c|c|c|c|}
\hline $\mathrm{P}, \%$ & 40 & 50 & 60 & 70 & 80 & 90 \\
\hline $\mathrm{d}(\mathrm{I})_{\mathrm{K}}, \mathrm{nm}$ & 1.9 & 2.28 & 2.85 & 3.80 & 5.7 & 11.4 \\
\hline $\mathrm{d}(\mathrm{II})_{\mathrm{K}}, \mathrm{nm}$ & 19.0 & 22.8 & 28.5 & 38.0 & 57.0 & 114.0 \\
\hline
\end{tabular}

Table 1 show that an increase in steel porosity leads to a noticeable increase in its surface layer thickness and an increase in the diffusion mobility of nitrogen. This steel can be obtained using powder metallurgy. In powder metallurgy, an important role is played by diffusion processes that ensure the formation of the structure of powder materials, especially in the production of alloys from a multicomponent mixture. When a homogeneous structure is obtained, the technological parameters of sintering should facilitate the diffusion homogenization of the alloy. In order to accelerate this process, it is necessary to 
create conditions for the most active types of diffusion to occur. In [12], the main regularities of the influence of the degree of porosity and the temperature of tests on the processes of local destruction (initiation of microcracks) - resistance to micro-cleavage and resistance of a crack to its development - of powder alloy steels were established. It is shown that there is a significant difference in the behavior of powder steel from ordinary steels in brittle fracture, which consists in an increase in the resistance to microspalling with a decrease in the test temperature.

\section{Conclusion}

It is shown that the thickness of the surface layer of the steel of the rods turns out to be less than $20 \mathrm{~nm}$ and dimensional effects begin to affect its physical properties, that is, it is a nanostructure. Dimensional effects in this layer cause the "classical" Fick equations to fail in the layer. For the first time, we considered the problem of one-dimensional diffusion in the case when the coefficient depends on the coordinate. The analytical solution of the first boundary value problem showed that diffusion in a nanometer-thick wafer differs significantly from a bulk sample. The accuracy of solving this problem is determined by the de Broglie wave, that is, on the order of (0.01-0.001) nm for metals and alloys. The solution to this problem showed that the diffusion mobility of nitrogen will be proportional to the thickness of the surface layer d. This value is associated with the crystal structure of the metal and, mainly, with its porosity. In our work, we have shown that an increase in the porosity of steel leads to a noticeable increase in its thickness of the surface layer and an increase in the diffusion mobility of nitrogen. Such steel can be obtained by powder metallurgy and used for the above rods.

\section{Acknowledgements}

This work was supported by the Ministry of Education and Science of the Republic of Kazakhstan. Grants No. 0118PK000063 and No. Ф.0781.

\section{REFERENCES}

1 Yurov V.M., Oleshko V.S. The impact of the environment on the contact potential difference of metal machine parts. Eurasian Physical Technical Journal, 2019. Vol. 16. № 1 (31). C. 99-108.

2 Makeeva O.V., Oleshko V.S., Fedorov A.V., Yurov V.M. Development of a device for determining work electron output. Eurasian Physical Technical Journal, 2020, Vol.17, No.1 (33). - P. 127-131.

3 Voroshnin L.G., Mendeleeva O.L., Smetkin V.A. Theory and technology of chemical heat treatment. - Minsk, New knowledge, 2010, 304 p.

4 Berlin E.V., Koval N.N., Seidman L.A. Plasma chemical heat treatment of the surface of steel parts. Moscow, Technosphere, 2012, $464 \mathrm{p}$.

5 Yurov V.M. The thickness of the surface layer of atomically smooth crystals. Physicochemical aspects of the study of clusters, nanostructures and nanomaterials, 2019, No.11, pp. $389-397$.

6 Divinsky S.V., Zakharov S.M., Shmatko O.A. Grain-boundary diffusion and segregation in sintered nanocrystalline materials with a hierarchical structure. Uspekhi fiziki metallov, 2006, Vol. 7, pp. 1 - 39. [in Russian]

7 Dokukin S.A., Kolesnikov S.V., Saletsky A.M. Diffusion of atomic dimers during the formation of a surface alloy Pt / Cu (111) // VMU, Series 3. Physics. Astronomy, 2019, No. 4. - P. 46-51.

8 Sharifova E.G., Silina O.V., Makarova K.V. Analysis of literature data on the study of ways to intensify the nitriding process. Master`s journal, 2015, No. 2, pp. $60-65$.

9 Bekman I.N. Higher mathematics: the mathematical apparatus of diffusion. Moscow, Yurayt Publishing House, 2017, 459 p. [in Russian]

10 Korotcenkov G. Porous Silicon: From Formation to Application: Formation and Properties, CRC Press, 2015, Part $1,423 \mathrm{p}$.

11 Yurov V.M. The thickness of the surface layer of porous silicon. Bulletin of al Farabi KazNU. Physics, 2020, No. 1(72), pp. $60-66$.

12 Volokonsky M.V., Mishin V.M. Influence of porosity and lowering of the test temperature on the characteristics of local fracture of powder alloy steels . International Journal of Experimental Education, 2015, No. 4-2, pp. $441-442$. 